Methods: From March 2015 to July 2017 we examined 42 patients with scleroderma, from which 37 filled the valorisation criteria of MMPI-II test. The data of MMPI-II scales and BDI-II was correlated with antropometric data, form of disease, disease duration, duration of RP, organ major manifestation, comorbidities, use of medication and immunological profile.

Results: In this study 37 patient were included (6 men, 31 women, mean of age $-58.8 \pm 10.6 y$., duration of disease $8,9 \pm 9.1$, duration of RP $13.9 \pm 13.4 y$.), 10 patient have diffuse, 27 patient limited form. Subjective perceived depression detected by BDI II test was present in 11 patients $(35 \%$, mild 6 , moderate 3 and 2 severe). Total BDI-II score correlated with anticentromer Abs $(p=0.05)$, total cholesterol $(p=0.008)$, LDL $(p=0.05)$ and gastrointestinal manifestation $(p=0.002)$. Positivity in domain - Hypochondria, Depression, Hysteria, Psychastenia and Social introversion was highly prevalent $(47-13 \%)$. This results of MMPI-II suggest a specific psychological profile of SSc patients. There was no correlation for age, subset of disease, cardiovascular manifestation, valvular damage and myositis. Smokers are much more introvert $(\mathrm{p}=0.012)$. Positivity of anti Scl70 Ab correlated with incredulity $(p=0.038)$, schizophrenia, hypomania and family disharmony $(\mathrm{p}=0.046)$. Positivity of anticentromer antibodies was connected with incredulity $(p=0.038)$, hypomania, alienation to family, egocentrism $(p=0.042)$, psychotic thinking, psychomotoric retardation $(p=0.037)$ and subscales of BDI-II test (Loss of pleasure, Self-Criticism, Self-Dislike). From organ manifestation, pulmonary hypertension correlated with himself degradation $(p=0.037)$. Gastrointestinal manifestation has the same correlation and BDI-II subscale-Guilt Feelings $(p=0.042)$. It is interesting, that absence of lung damage demonstrated with alienation self and family $(p=0.049)$, posttraumatic stress disorder $(p=0.025)$, problems in family (in more scales, $p=0.028,0.03,0.029)$, schizophrenia $(p=0.03)$. Patients without digital ulceration have much more neurologic symptoms $(p=0.023)$. Using of antidepressant and anxiolitic medication correlated with a lot of scales in domain of depression, anxiety, social introversion, family distress and self devaluation. Disease duration and duration of RP correlated with psychomotoric retardation. Conclusions: Patients with scleroderma may have special psychological profile. MMPI-II test shows specific psychologic abnormalities of scleroderma patients. Psychiatric and psychologic intervention can be very useful in complex care of these patients.

Acknowledgements: MZ CR VES15-28659A.

Disclosure of Interest: None declared

DOI: 10.1136/annrheumdis-2017-eular.6528

\section{AB0610 NAILFOLD CAPILLARY MICROSCOPY AND LOW BODY MASS INDEX IN RAYNAUD'S PHENOMENON PATIENTS}

A.M. Van Roon ${ }^{1}$, A. Eman Abdulle ${ }^{1}$, A.M. van Roon ${ }^{1}$, A.J. Stel ${ }^{2}$, A.J. Smit ${ }^{1}$, H. Bootsma ${ }^{2}$, D.J. Mulder ${ }^{1}$. I'Internal Medicine - Vascular Medicine;

${ }^{2}$ Rheumatology and Clinical Immunology, University of Groningen - University Medical Center Groningen, Groningen, Netherlands

Background: Underweight patients develop Raynaud's phenomenon (RP) more frequently. [1] In a small study, skin temperature and perfusion in RP patients was positively associated with body mass index (BMI). [2] In clinical practice, we frequently observe an abnormal nailfold capillary microscopy (NCM) in underweight subjects with presumably primary RP, from which the implications are unknown.

Objectives: The aim is to study whether being underweight is associated with the presence of more abnormalities on NCM.

Methods: NCM, assessed by widefield videocapillaroscopy, was retrospectively assessed in consecutive patients with suspected RP. Patients were included when they had negative serology and did not develop any definite connective tissue disease or organ involvement after a maximum of 5 years follow-up. NCM pattern was classified as normal, non-specific, early, active or late, based on the Cutolo patterns. Weight and height were measured for clinical practice and patients were divided by BMl category: underweight $\left(\mathrm{BMl}<18.5 \mathrm{~kg} / \mathrm{m}^{2}\right)$, normal weight (BMI $\left.18.5-25 \mathrm{~kg} / \mathrm{m}^{2}\right)$, and overweight $\left(\mathrm{BMI}>25 \mathrm{~kg} / \mathrm{m}^{2}\right)$. Dilated and giant capillaries were counted as well as the total number of capillaries.

Results: A total of 352 patients were included (median age 40.6 years (24.952.9), male/female: 111/241), of which 47 were underweight, 220 normal weight and 85 overweight. Patients who were underweight presented more abnormalities (dilated capillaries, capillary loss or giant capillaries) on NCM, as shown in figure 1. BMI was negatively associated with NCM pattern, number of dilated capillaries and number of giant capillaries $(r=-0.247, r=-0.225$ and $r=-0.221$ respectively, all $p<0.001)$ and positively with the total number of capillaries $(r=0.260, p<0.001)$. Conclusions: In addition to well-known thermoregulatory abnormalities, clear NCM pattern abnormalities are more frequently observed in underweight patients with primary RP. BMI was negatively associated with the number of dilated capillaries and positively with capillary density. These data potentially suggest that damage to the microvasculature in underweight patients with primary RP may occur independently of the presence or development of a CTD and may be explained by other mechanisms.

\section{References:}

[1] Roquelaure Y, Ha C, Le Manac'h AP, Bodin J, Bodere A, Bosseau C, et al. Risk factors for Raynaud's phenomenon in the workforce. Arthritis Care Res (Hoboken) 2012 Jun;64(6):898-904.

[2] Giurgea GA, Mlekusch W, Charwat-Resl S, Mueller M, Hammer A, Gschwandtner ME, et al. Relationship of age and body mass index to skin temperature



and skin perfusion in primary Raynaud's phenomenon. Arthritis Rheumatol 2015 Jan;67(1):238-242.

Disclosure of Interest: None declared

DOI: 10.1136/annrheumdis-2017-eular.3243

\section{AB0611 MYCOPHENOLATE MOFETIL FOR THE TREATMENT OF INFLAMMATORY MYOPATHY RELATED INTERSTITIAL LUNG DISEASE: A SYSTEMATIC REVIEW}

B. Lopez ${ }^{1}$, D.A. Isenberg ${ }^{2}$, P.A. Gordon ${ }^{1} .{ }^{1}$ Rheumatology, King's College Hospital; ${ }^{2}$ Rheumatology, UCL, London, United Kingdom

Background: Inflammatory myopathies (IIM) are a heterogeneous group of rare autoimmune rheumatic diseases in which extramuscular manifestations, especially interstitial lung disease (ILD), are common and may occur in the absence of muscle symptoms. ILD has been identified as a marker of poorer prognosis, with sparse, mainly observational evidence, supporting the use of immunosuppressant therapies.

Despite the lack of clinical trial evidence, corticosteroids are considered first-line therapy. Cyclophosphamide is frequently used for severe disease and Azathioprine as maintenance therapy. Mycophenolate Mofetil (MMF) has emerged as a promising treatment, encouraged by data published from a randomised controlled trial comparing Cyclophosphamide with MMF in patients with systemic sclerosis and ILD, which showed similar efficacy and better tolerability in the MMF group (1)

Objectives: To examine the evidence supporting the use of MMF in patients with IIM associated ILD.

Methods: An electronic literature search was performed using the Ovid platform Population: Adults diagnosed with IIM according to validated criteria $(2,3)$ or antisynthetase syndrome (defined by the presence of anti-synthetase antibodies), with ILD demonstrated by HRCT or lung biopsy and treated with MMF, with extractable outcomes regarding ILD. Outcomes were recorded as positive (improvement/stabilisation) and negative (deterioration) as defined by the American Thoracic Society consensus guidelines (4).

Results: 506 initial citations were identified, with 23 studies included in the review comprising a total of 82 patients. Median follow up was 12 months, median age 55 years. There was sufficient data to apply America Thoracic Society criteria in 37 patients: improvement/stabilisation $n=29$, deterioration $n=8$. Although the criteria could not be applied in 45 patients, improvement/stabilisation was reported in 44 with deterioration in one patient. A non-significant trend to better outcomes was observed when MMF was prescribed as first line therapy, in Jo-1 positive patients and non-Usual Interstitial Pneumonia pattern. Mean Prednisolone dose reduced from $40 \mathrm{mg} /$ day to $10.1 \mathrm{mg} /$ day. No significant toxicity was reported.

Conclusions: Mycophenolate Mofetil is a promising drug with encouraging results, but randomised controlled clinical trials are needed to prove its efficacy.

\section{References:}

[1] Tashkin DP, Roth MD, Clements PJ, Furst DE, Khanna D, Kleerup EC, et al. Mycophenolate mofetil versus oral cyclophosphamide in scleroderma-related interstitial lung disease (SLS II): a randomised controlled, double-blind, parallel group trial. Lancet Respir Med. 2016;4(9):708-19.

[2] Bohan A, Peter JB. Polymyositis and dermatomyositis (first of two parts). N Engl J Med. 1975;292(7):344-7.

[3] Sontheimer RD. Would a new name hasten the acceptance of amyopathic dermatomyositis (dermatomyositis siné myositis) as a distinctive subset within the idiopathic inflammatory dermatomyopathies spectrum of clinical illness? J Am Acad Dermatol. 2002;46(4):626-36

[4] American Thoracic Society. Idiopathic pulmonary fibrosis: diagnosis and treatment. International consensus statement. American Thoracic Society (ATS), and the European Respiratory Society (ERS). Am J Respir Crit Care Med. 2000;161(2 Pt 1):646-64.

Disclosure of Interest: None declared

DOI: 10.1136/annrheumdis-2017-eular.6327 